\title{
The Hope of the Country with a Large Population: Theories and Practices of China's Population Transformation
}

\author{
by Xueyuan Tian \\ Social Sciences Academic Press (China) and \\ Heidelberg: Springer-Verlag Berlin, 2014 \\ ISBN 978-3-642-40831-1 \\ Hardcover, \$99, 296 pp.
}

Reviewed by Jing Shen

University of Lethbridge

The Hope of the Country with a Large Population focuses mainly on China's population trends and policies in the 1990s. With significant demographic changes in the present Chinese society, a historical review of demographic composition and development in the past three decades could always be helpful in terms of deepening one's understanding of the demographic structure and policies in China today.

This book includes seven chapters. The first chapter covers the theoretical framework of the book. In this chapter, the author focuses on the New Population Theory proposed by Ma Yinchu, and articulates the legitimacy of China's one-child policy that was strictly implemented from the end of the 1970s to the 1990s. The second chapter describes China's demographic structure in the 1990s, in which period the Chinese population was relatively young, so that the one-child policy contributed positively to the national economy. The third chapter focuses on population aging and elder care, particularly regarding the rapid speed, high level, and accumulated growth of aging, as well as the unbalanced distribution of the aging population between rural and urban areas. The fourth chapter discusses the population flow from the rural to urban area as the main characteristic of China's urbanization process in the 1990s. From chapters 5 to 7, the author turns his attention to population policies. In addition to re-emphasizing the suitability of the one-child policy in the context of China's changing demographic structure in the 1990s, the author also makes an attempt to predict China's demographic development based on the influences of the one-child policy.

Certainly, the Chinese population has changed tremendously since the 2000s. For example, the growth of the elder population has been much more rapid than what was predicted by the author. In fact, the most recent change in the one-child policy that allows a couple-if one of them is an only child - to have a second child has shown the government's concern about the fast-aging population in the current society. Urbanization does not seem to follow the "special S-curve" path pointed out by author, either. On the contrary, regional disparities and the rural-urban gap have worsened since the early 2000s. The increasing social inequalities have, in turn, caused socio-demographic consequences that the author failed to predict in this book. For instance, a comparative study based on data 
drawn from the China General Social Surveys between 2005 and 2010 shows that self-reported health has worsened among the disadvantaged, including women, elders, and rural residents, as economic inequality increased (Bian and Shen 2015). While mortality due to malnutrition and/or poor medical conditions has decreased significantly since the socioeconomic reforms, mortality due to heart diseases, cancer, and other pollution-related diseases has increased drastically. These new challenges cannot be addressed by a traditional population policy that simply emphasizes quantity control.

Regardless, with its focus on population trends and policies in the 1990s, this book provides useful historic evidence that makes sense of the demographic issues in the present Chinese society. Further research that focuses on comparing this book and studies on population issues after the 2000s would be of great importance for us to understand the historic background, status quo, and trajectory of China's demographic development.

\section{Reference}

Bian, Y.J., and J. Shen. 2015. Felt-suffering and its social variations in China, in World Suffering and Quality for Life, edited by R. Anderson. Dordrecht: Springer Netherlands, p. 187-202. 